\title{
Split cord malformations: From the surgical viewpoint
}

\author{
Adem Doğan 1, Soner Yaşar ${ }^{1}$, Alparslan Kırık ${ }^{1}$, Cahit Kural ${ }^{1}$, Mehmet Ozan Durmaz ${ }^{1}$, Ali Kaplan ${ }^{1}$, Şahin \\ Kırmızıgöz ${ }^{1}$, Sait Kayhan ', Gardashkhan Karımzada ${ }^{1}$
}

(1) University of Health Sciences, Neurosurgery, Ankara, Turkey

Date submitted:

Jul 06, 2019

Date accepted:

Jul 26, 2019

Online publication date:

December 15, 2019

\section{Corresponding Author: \\ Adem Doğan \\ University of Health Sciences, \\ Neurosurgery, Ankara, Turkey \\ drademdogan@yahoo.com}

Keywords: Split cord malformation, Diastematomyelia, Diplomyelia, Surgery.

\begin{abstract}
Aims:Split cord malformations (SCM) are congenital anomalies of the spine. The spinal cord is divided into two hemicords in the vertical plane. With foot and spine deformities, the skin lesions on the midline, even at the level of the lesion, at the back are the main signs of SCM. It is divided into two types as Type I (Diastometamyelia) and Type 2 (Diplomyelia). We retrospectively reviewed our cases with SCM and presented our results.

Methods:In our department, 27 cases of SCM in 2012-2018 were surgically treated. Of these, 23 were Type I, 4 were Type II. In type I SCM, the bone septum was removed, the hemicords were assembled in a single dura, and the spinal cord was released. In type II SCM, fibrous band was removed and spinal cord was released.

Results:All patients were recovered well after surgery. No mortality had been occured. Cerebrospinal fluid (CSF) fistula was seen in 4 patients. The complications such as CSF fistula, infection or wound problems were properly managed.

Conclusions:In this paper, we tried to mention about preoperative preparation, intraoperative surgical steps and postoperative period of SCMs. Surgical technique and steps were especially emphasized. SCMs should be treated surgically as soon as possible after the birth in order to avoid neurological and urological deterioration.
\end{abstract}

\section{Introduction}

Split cord malformations (SCM) are rare spinal malformations. There are 2 types of SCM. Type 2 SCM is a congenital anomaly in which the spinal cord is divided into two neural tubes with a fibrous band in the sagittal plane along one or more vertebrae within the single dural sheath. In case the spinal cord is divided into two hemicords, the anomaly surrounding both hemispheres and individual dural sheaths is called Type 1 SCM. In about $10 \%$ of the cases, the spinal cord is in two parts without any distinctive tissue (1).

Among the theories about the development of SCM, the most popular is the continuation of the nothochord's split into two, and the ectoderm of the skin just above the two separate note scopes as a result of the remaining of the neuro-enteric channels (Kovalevsky channels), which must have existed for a day or two, during the gastrulation. two different regions of the nervous system to send signals about the development (1).

Segmental anomalies are frequently associated with diastematomyelia. They cause a variety neırological disorders such as loss of strength, loss of sensation, deep tendon reflexes, foot deformities or urinary and anal incontinence. The diagnosis is usually madein childhood $(1,2)$. The skin has hypertrichosis and discoloration. It may also be associated with a dermal sinus or subcutaneous lipoma. Computed tomography (CT) showed that the septum and magnetic resonance imaging (MRI) revealed the spinal cord continued in two separate hemicords (2).

Surgical treatment is the removal of the bone septum or fibrous band together with the dural sheath around the hemicords (3-5). The main aim of the surgery is to untether the spinal cord and to prevent further neurological or urological deficits (6-10). Microsurgical techniques and intraoperative neuromonitoring are the vital components of surgery.

In this study, we retrospectively reviwed 27 cases of SCM who underwent surgical treatment. We presented their results and we especially focused on the surgical technique.

\section{Methods}

This study has been approved by the Gulhane Non-Interventional Ethical Committee (No:18/346, Date: 08.01.2019). This retrospective study has been carried out in accordance with 
The Code of Ethics of the World Medical Association (Declaration of Helsinki) for experiments involving humans (link- https:// www.wma.net/policies-post/wma-international-code-of-medical-ethics/), and Uniform Requirements for manuscripts submitted to Biomedical journals (link- http://www.icmje.org/). Informed consent for surgery was obtained from the patients or their legal guardians.

\section{Patients}

In this study, we retrospectively reviewed 27 cases of SCM who were operated in our clinic between 2012-2018. 14 of them were female and 13 were male.The mean age was 8.3 year (ranged 1 day-22 years). The smallest patient was 1-day old and the oldest was 22 years old. Eight of the patients were in the neonatal period (0-20 days). All patients in the neonatal period presented with skin lesions. However, the most common presenting symptom in our series was gait disturbance. In addition, hypertrichosis on the thoracic or lumbar region was frequently present at admission to the hospital (Table 1). The most common findings were gait disturbance, ataxic gait, difficulty in crawling. In 8 patients, the length and width of the lower extremities were different. Two patients had previous surgery in the thoracolumbar region (both patients had previously been operated for meningomyelocele). In 18 patients, the malformation level was lumbar region, 8 patient in thoracic region and 1 in cervical region (Figure 1) (Table 2). 23 patients had type 1 SCM (Figure 2), 4 had type 2 SCM. All cases were accompanied by at least one additional malformation. The most common accompanying malformation was tethered cord syndrome (18 patients). Subsequently, meningomyelocele was present (7 patients). Myeloschisis, congenital hip dysplasia, scoliosis, Arnold-Chiari syndrome were also seen other malformations. In addition, dermal sinus in one patient, sacral agenesis in 1 patient and perineural cystic lesion (Tarlov cyst) in 1 patient (Table 3).

\begin{tabular}{|lc|}
\hline \multicolumn{2}{|l}{ Table 1. Complaints at admission of patients with SCM. } \\
\hline Complaint at Admission & Number of patient (\%) \\
\hline Walking disturbance & $12(44)$ \\
\hline Skin defect & $9(33)$ \\
\hline Hypertrichosis & $5(18.5)$ \\
\hline Urinary incontinence & $3(11.1)$ \\
\hline Dermal sinus tract & $2(7.4)$ \\
\hline
\end{tabular}

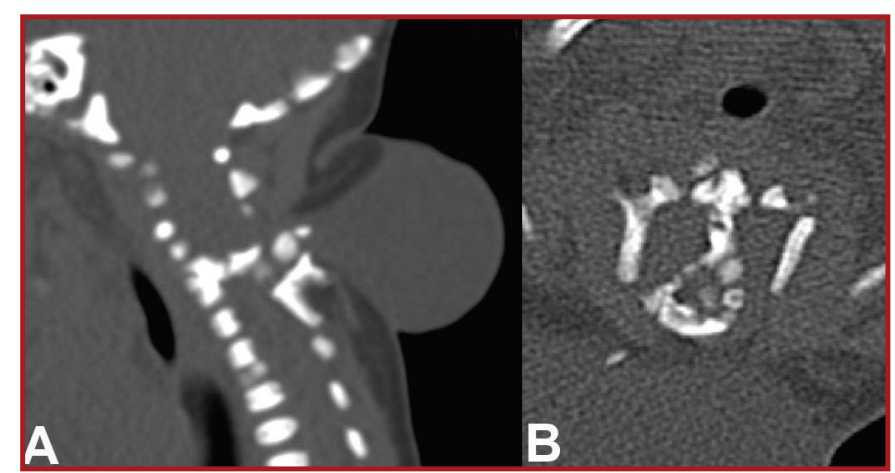

Figure 1. Preoperative sagittal (A) and axial (B) CT scans of a newborn with cervical meningocele and Type $1 \mathrm{SCM}$. It is clear that the bony septum was not ossified and in a fragmented structure.

\begin{tabular}{lc}
\hline Table 2. Level of SCM. \\
\hline Spinal level (Region) & Number (\%) \\
\hline Cervical & $1(3.7)$ \\
\hline Thoracic & $8(29.6)$ \\
\hline Lumbar & $18(66.6)$ \\
\hline
\end{tabular}

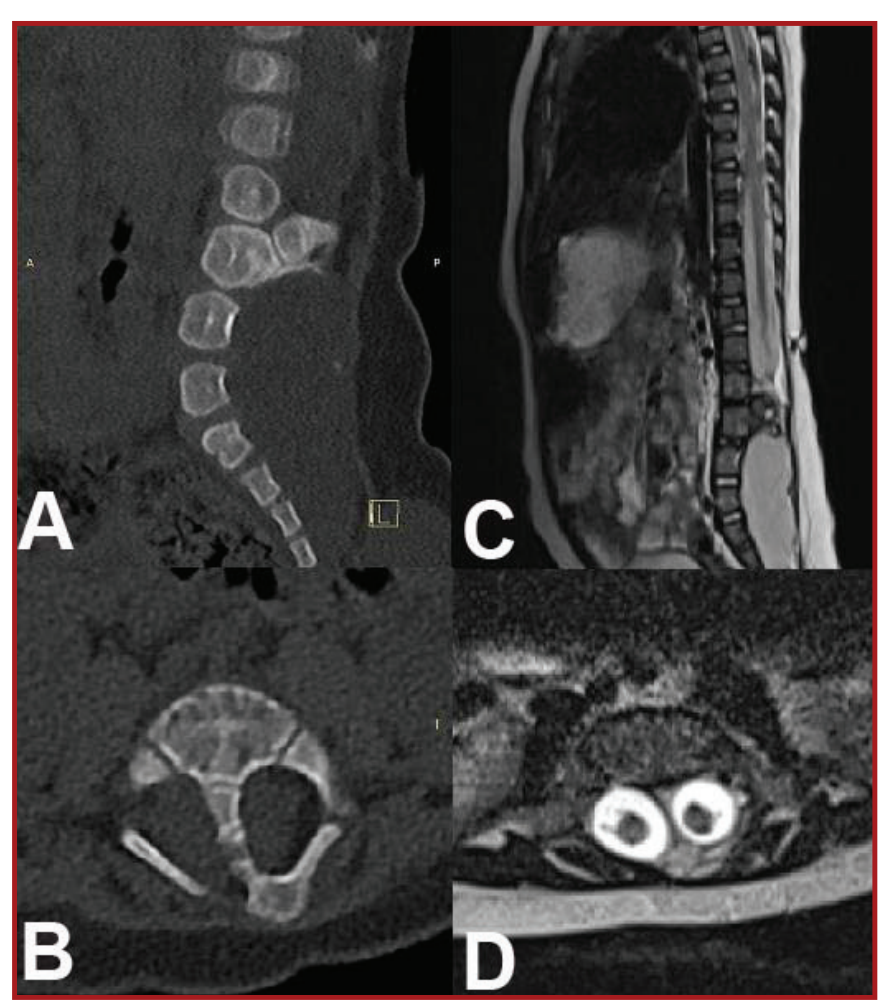

Figure 2. The sagittal (A) and axial (B) CT scans of a child with Type 1 SCM showed bony septum at L3 level. Note that the septum was not fused with corpus. Sagittal (C) and axial (D) MRI scans revealed that the 2 hemicords were within the 2 separate dura maters.

Table 3. Associated malformations observed with SCM

\begin{tabular}{lcc}
\hline Associated malformation & Type 1 SCM & Type 2 SCM \\
\hline Tethered cord syndrome & 15 & 3 \\
\hline Myelomeningocele & 6 & 1 \\
\hline Hydrocephalus & 4 & 1 \\
\hline Myeloschisis & 2 & - \\
\hline Congenital hip dysplasia & 2 & - \\
\hline Scoliosis & 1 & - \\
\hline Arnold-Chiari Malformation & 1 & - \\
\hline Spinal Extradural Cyst & 1 & - \\
\hline Sacral Agenesis & 1 & - \\
\hline Dermal Sinus tract & 1 & - \\
\hline Corpus callosum agenesis & 1 & - \\
\hline
\end{tabular}

\section{Preoperative Evaluation}

Preoperative CT and/or MRI techniques were applied to all patients. Preoperative electrophysiological studies could not be 
performed in 14 cases (newborns and infants). In 11 of 13 patients who underwent somatosensory evoked potential (SEP), bilateral tibial responses were prolonged. SEP measurements were performed in other cases. After the physical, neurological, radiological and electrophysiological evaluation, all patients underwent standard surgical treatment.

\section{Surgical procedure}

Standard surgical technique was used for all cases of SCM. Intraoperative neuromonitoring and microsurgical techniques were essential in our operations. In Type I, the bony septum was removed first. In this step, high speed drill was used in patients older than 18 years in order to remove the dense and rigid septum. But in children, it was easy because of the less ossification and fragmented structure of bony septum (Figure 1). The feeding artery of the septum was also coagulated while removing the septum. Then, the dural sleeve was opened and the hemicords were inserted in one single neural tube. During this step, the paramedian nerve roots which were neurologically inactive and attached to the dura were cut and the hemicords were released. After closing the dura mater, the filum terminale was found at L5-S1 level and confirmed using electrical stimulation. The filum was cut and the spinal card was released. This procedure was performed under microsurgery and intraoperative neuromonitoring. The intact and functional neural roots were preserved by monitoring. In Type 2, after the dural opening, the fibrous band which divided the spinal cord into 2 hemicords was removed under microsurgery. During this step, the median non-functional nerve roots were isolated and cut. The filum was also cut in this procedure after the removal of fibrous band. In all acses, a small portion of filum terminale was sent to pathology department for further investigation.

\section{Postoperative Period}

No complication occurred in the early postoperative period in 19 cases. Four patients had a wound dehiscence. In 4 patients, the cerebrospinal fluid (CSF) fistula was accompanied by the wound site. These cases were improved with dressing follow-up. However, dura repair and wound site revision were performed in patients who had CSF fistula without closure using dressing. In one patient, meningitis was appeared in this period. She was treated with antibiotics. Nineteen cases other than 8 patients in the neonatal period were hospitalized in our own clinic and the duration of hospitalization was analyzed more objectively. Accordingly, the shortest hospital stay was 5 days and the longest was 16 days. The mean hospital stay was 7 days. Four of the patients who underwent routine follow-up from the postoperative 1st month developed hydrocephalus with diffuse ventricular enlargement and flickering of the optic discs during cranial CT imaging at different control periods (3 of these cases were in the neonatal period and presented with an increase in head circumference). These patients had ventriculoperitoneal shunt. One patient had a ventriculoperitoneal shunt before admitting to our center. Shunt dysfunction developed in one patient and shunt revision was performed.

\section{Results}

In all cases, SCM was surgically managed and the spinal cord was released. In Type 1 cases, the septum was in the bone structure, and in Type 2, it was fibrous or arachnoid band. Three patients with type 1 SCM and 15 patients with Type 2 SCM had thick filum terminale. In these cases the filum was cut and released. Meningomyelocele was present in 7 cases and meningomyelocele sac was excised and the neural placode was reconstructed. Dermal sinus tract was found in 1 case and sinus tract was excised. In one patient with Type 1 SCM, extradural cystic lesion (Tarlov cyst) was detected and excised during surgery. There was no neurological deterioration in the postoperative period. SEP measurements could be performed in 12 patients from the first postoperative month (all patients who underwent SEP measurement in the preoperative period). Bilateral tibial responses returned to normal in 6 patients (11 cases) with prolonged bilateral tibial response.

No neurological deterioration was occured in any patient and there was no mortality in ours series. The complications such as CSF fistula, infection or wound problems were properly managed.

\section{Discussion}

\section{Embyological Factors}

The term diastematomyelia was first used in 1837 by Ollivier (11) and then by Hertwig (12). After using this term for many years, the term diplomyelia, which means double spinal cord, has been used. SCM is a congenital anomaly of the spinal cord. Briefly, a fibrous band on the longitudinal axis of the spinal cord can be defined as the separation of cartilage or bone tissues into two separate segments in the midline. Pang et al. suggested that SCM was the result of incomplete regression of the primitive neuroenteric canal in 1992 and described two types of SCM (7). There are two fully separated hemicords (half-spinal cord) and both spinal cord is wrapped with its own dural sheath. This type corresponds to "diastematomyelia". In type 2, however, there are two hemicords, but they are in the same dural sheath and separated by a thin, elastic fibrous band. This type corresponds to "diplomyelia" $(3,6,7,10,13,14)$.

Embryologically; all types of SCM result from a major ontogenetic error in the closure of the primitive neuroenteric duct during the gastrulation of embryonic life (7). The septum separating both hemicords is located in the lumbar vertebra at a rate of $70 \%$, and the second most commonly located in the thoracolumbar junction. Similarly, in our study, it was seen most frequently in the lumbar region and 66 percent. Very rarely, the upper thoracic or cervical region may also have septum $(15,16)$. One patient usually has only one type of SCM. Sometimes there may be septum at multiple levels. More rarely, in some patients, both types of SCM may be observed at the same or different levels together. These are called "composite type"SCM $(2,17)$. No composite type was seen in our cases.

\section{Associated malformations}

SCMs are usually seen with tethered cord syndrome (18). The conus level is often below the L1-L2 and the filum is usually thick or fatty. In addition, there may be concomitant scoliosis, myelomeningocele, meningocele, malformations such as syringomyelia or tumors such as teratoma $(14,18,19)$. No teratoma or syringomyelia was seen in our cases. However, additional malformations such as congenital hip dislocation, sacral agenesis and Arnold-Chiari malformation were observed. Therefore, SCM cases should be carefully evaluated clinically and radiologically and surgery should be planned accordingly. In our series, the conus was below the normal level in 18 cases. Myelomeningocele was associated with six Type 1 and one Type 2 SCM pediatric cases. In these cases, meningomyelocele sacs were excised in the same session. 


\section{Surgical technique}

The treatment of SCMs is surgical. Malformation should be corrected by operating at the youngest age possible (10). When SCM is diagnosed with or without neurological, urological or orthopedic problems, it is recommended that it be operated $(3,8,10)$. Prophylactic surgery is especially necessary in pediatric patients $(10,20,21,22)$. In adult patients, surgical treatment should be considered because of the risk of neurological and urological deficits due to pain and increasing spine deformities with age. As the risk of developing neurological or urological deficits increases with advancing age, especially due to minor traumas, early operation is recommended $(6,10)$.

Surgical method has been described in the literature $(2,22)$. Extradural excision of the septum, closure of the hemicords into a single dural sheath, and release of the spinal cord are the basic surgical steps in Type 1 SCM. In Type 2 SCM, first the dura is opened and the fibrous band is excised, then the spinal cord is released. In composite type SCM, firstly the upper septum and then the lower septum are excised and the lastly filum is released (17). In SCM with dorsal septum, after the septum has been excised, dura should be opened and the presence of fibrous band should be investigated (20). In no case of SCM, first the filumis released and then the septum is excised, otherwise irreversible neural deficits may occur. In addition, after the septum has been excised, the spinal cord should be released if the conus is lower than normal level or if the filum is thick and taut. Patients in whomthese steps are not performed are, then, re-operated and the patients experience the risks and stress of a second surgery. Sometimes the bony septum can cut into the dura as oblique. In these cases, part of the septum may be left in place. The important thing is that there is not enough septum to separate or enforce the hemicords. After removal of the septum, the dura must be opened in a "fish mouth"style and both hemicords should be exposed and all fibrous bands should be cut and the spinal cord should be released. In addition, accompanying pathologies such as myelomeningocele manqué, teratoma and meningocele should be repaired in the same session. In our study, the sac was excised in meningomyelocele-associated cases.

$\mathrm{CT}$ and MRI are recommended for postoperative follow-up period. In patients with type $1 \mathrm{SCM}$ who underwent surgery and underwent septum excision, re-enlargement of the septum may occur in later years (21). These cases should be followed up with $\mathrm{CT}$ and patients with septum enlargement should be reoperated if necessary. MRI is especially important in monitoring the conus level and in observing intradural adhesions, especially in tense spinal cord cases (14). In some cases, septum has been re-enlarged and has not been reoperated due to its asymptomatic nature (2). In addition, cranial CT should be performed at certain periods postoperatively, especially from the first month, and patients should be followed up for hydrocephalus. As a matter of fact, hydrocephalus developed in 4 patients and ventriculoperitoneal shunt was inserted in our series.

\section{Conclusion}

SCM is a rare and complex spinal anomaly with many additional malformations. Prophylactic surgery is required. Surgical management of associated malformations is also important. Early diagnosis and treatment prevents possible neurological and urological deficits in later years. Surgery of SCM is quite different from the classical spinal surgery and requires surgical skills and experience. The support of electrophysiological monitoring during surgery is essential. In addition, it should be remembered that hydrocephalus may occur in the post-SCM surgery period.

\section{Acknowledgments}

We want to thank Prof. Mehmet Daneyemez for his contribution to our education and training. The contributions of the authors were; General supervision of research: AD, AK, GK; writing assistance: SY; data collection: AK, CK, ŞK, SK, MOD; responsibility for presentation and logical explanation of results: $A D$; final approval of the manuscript: SY, AK, MOD.

\section{Conflict of Interest}

The authors have nothing to disclose regarding conflict of interest with respect to this manuscript.

\section{References}

1. Selcuki M. Split cord malformations. In: Basic Neurosurgery. 1st ed. Ankara: Turkish Neurosurgical Society Publications; 2010: 1889-1890.

2. Kural C, Solmaz I, Pusat $\mathrm{S}$, et al. Surgical technique for split cord malformations: Pitfalls and solution pathways. Gulhane Med J 2013;55(2):77-83

3. Ersahin Y, Mutluer S, Kocaman S, Demirtaş E. Split cord malformations in children. J Neurosurg 1998; 88(1): 5765

4. Meyrat BJ, Vernet O, Berger D, de Tribolet N. Pre- and postoperative urodynamic and anorectal manometric findings in children operated upon for a primary tetherd cord. Eur J Pediatr Surg 1993; 3(5):309-312

5. Pang D, Wilberger JE. Tethered cord syndrome in adults J Neurosurg. 1982; 57(1): 32-47

6. Tatı M, Güzel A, Karadağ Ö. Ayrık omurilik malformasyonları. CÜ Tıp Fakültesi Dergisi 2004; 26(2): 98-102.

7. Pang D, Dias MS, Ahab-Barmada M. Split cord malformation: Part I: A unified theory of embryogenesis for double spinal cord malformations. Neurosurgery 1992; 31(3): 451-480.

8. İci Y, Gönül M, Gönül E. The diagnostic value of Skin lesions in split cord malformations. J Clin Neurosci. 2007; 14(9): 860-863.

9. Sinha S, Agarwal D, Mahapatra AK. Split cord malformations: An experience of 203 cases. Childs Nerv Syst 2006; 22(1): 3-7.

10. Turhan T, Erşahin Y. Ayrık omurilik malformasyonları. Türkiye Klinikleri J Neurosurg-Special Topics 2011; 4(1): 31-37

11. Ollivier CP. Traites des maladies de la moelle epiniere. 3rd ed. Paris: Mequignon-Marvis; 1937

12. Hertwig O. Urmund und spina bifida. Arch Mikr Abat 1892; 39: 353-503

13. Jindal A, Mahapatra AK. Split cord malformations-a clinical study of 48 cases. Indian Pediatr 2000; 37(6):603607.

14. Özek MM, Pamir MN, Özer AF, Keles GE, Erzen C. Correlation between computed tomography and magnetic resonance imaging in diastematomyelia. Eur $\mathrm{J}$ Radiol 
1991; 13(3): 209-214.

15. Orakdöğen $M$, Türk CC, Erşahin $M$, Biber $N$, Berkman Z. Spinal dysraphisms of the cervicothoracic region in childhood. Turk Neurosurg 2009; 19(4): 400-405.

16. Akay KM, İzci Y, Baysefer A, Timurkaynak E. Split cord malformation in adults. Neurosurg Rev 2004; 27(2): 99105.

17. Akay KM, İzci Y, Baysefer A, Timurkaynak E. Composite type of split cord malformation: Two different types at three different levels: Case report. J Neurosurg 2005; 102(4 Suppl): 436-438.

18. Öztürk E, Sönmez G, Mutlu H, et al. Split-cord malformation and accompanying anomalies. J Neuroradiol 2008; 35(3): 150-156.

19. Proctor MR, Scott RM. Long-term outcome for patients with split cord malformation. Neurosurg Focus 2001; 10(1):e5.

20. Akay KM, Izci Y, Baysefer A. Dorsal bony septum: A split cord malformation variant. Pediatr Neurosurg 2002; 36(5): 225-228

21. Gupta DK, Ahmed S, Garg K, Mahapatra AK. Regrowth of septal spur in split cord malformation. Pediatr Neurosurg 2010; 46(3): 242-244.

22. Boop FA, Chadduck WM. Repair of diastematomyelia. In: Rengachary SS, Wilkins RH (eds). Neurosurgical Operative Atlas. Vol: 3. AANS Publications Committee. Baltimore: Williams\&Wilkins; 1993: 221-225. 